\title{
New literacies for connected learning in global classrooms
}

\author{
Toni Downes and Katina Zammit \\ University of Western Sydney, P.O. Box 555 Campbelltown, NSW 2560 Australia. \\ t.downes@uws.edu.au,k.zammit@uws.edu.au
}

\begin{abstract}
While much is being researched and written about the nature of new learning environments and the changing roles for teachers in the school of the future little serious attention is being paid to the new demands being placed upon students in secondary schools as they communicate, handle information and learn in global networked classrooms. In secondary schools, teachers expect to build on students' existing literacy skills and understandings. These skills and understandings are essentially built around the paper-based technologies of pen, paper, books and libraries. Learning processes in networked learning environments require substantially different literacies. The key differences relate to the changing nature of texts with which students will need to work. This paper will discuss the implications for secondary curricula and pedagogy of the challenges presented by the literacy demands these "new texts" place on secondary school students in networked learning environments. In particular it will argue for a redefinition of basic literacies and learning processes taught and used in secondary classrooms.
\end{abstract}

Keywords: Literacies, secondary, learning environments, networked classrooms

\section{LITERACY AND LEARNING IN SCHOOL}

Historically to be literate in Western society has meant that an individual has a capacity to read and write at a level that enables them to learn formally within educational institutions and to effectively participate as a worker and citizen. Within Australian schools while it has been accepted that learning about subject areas occurs through literacy, it has been assumed that secondary school teachers were working with literate individuals. Learning

The original version of this chapter was revised: The copyright line was incorrect. This has been corrected. The Erratum to this chapter is available at DOI: 10.1007/978-0-387-35403-3_29 
about the components of literacy was considered a task for primary schooling. In recent years, this has changed such that today most secondary school teachers believe that within the context of teaching their particular subject matter, they too are teachers of literacy.

Accompanying these changes have been developments in the theoretical framework surrounding literacy education. These relate to the addition of socio-cultural and critical aspects to the historical definition of literacy. The socio-cultural component expands the concept of literacy to include the social practices and conceptions that surround reading and writing. As such literacy has many forms according to different contexts, as readers engage with different types of written texts, such as newspapers, novels or instructions on food packaging. In this sense different literacies exist and they are inextricably connected to purposes and practicalities of use. This approach has led to a growing understanding of how and why various social groups have different and unequal access to literacy (and knowledge). Thus a further dimension has evolved, critical literacy. Critical literacy includes the skills and understandings needed to analyse and evaluate texts and the wider social practices made possible through the reading and writing of particular texts.

In the past two decades there have also been significant changes in practices associated with literacy learning in Australia. The early changes related to major shifts in teaching strategies. For example, there was a move away from drill and practice to whole language and now to genre-based approaches. The more recent changes reflect the broader understandings of the socio-cultural and critical components of literacy. Many educators now accept that literacy is not just a set of cognitive abilities or skills based on an identifiable technology, e.g. alphabetic script, but also a social activity embedded within larger social practices. Making meaning has as much to do with socio-cultural processes as with internal cognitive events (Lankshear, 1997). Hence the literacy demands and practices in secondary school are different in each subject area. The geography teacher and students learn about and work with a range of particular practices and texts types to develop and demonstrate skills and understandings central to the discipline of geography. The science and art teachers and students learn about and work with others.

The increasing understanding of the role of critical literacy has seen many of the practices associated with literary studies and media studies now being applied to other types of texts in the various subject areas. Students now attend to the way texts "talk about" people, places, events and phenomena and "talk to" the reader, whether they be literary or factual texts. For example, when working with historical texts which retell events of World War II students analyse the text not only for its content, but also for 
its purpose and audience, and the techniques it uses to position the people and events within particular ideological frameworks.

Significantly within these shifts to the socio-cultural and critical, the concept of literacies still refers to the reading and writing of paper-based texts within a particular culture. In this sense the notion of a literate person remains interconnected with the technologies of paper, pen, books and libraries and the social practices surrounding reading and writing within a particular cultural community. Essentially, the new ICT has been ignored as has the impact of globalisation and the issue of inter-cultural understandings. Consistent with this, literacy practices in secondary classrooms have been, and generally continue to be, based on competencies and social practices surrounding paper-based technologies in particular cultures. Today's global digital society demands a further re-definition of literacy and places significant stress on traditional practices in schooling.

New digital and network technologies have come into the workplace, home and school as major information and communication technologies. This ICT is placing new demands on students, workers and citizens who need to be able to communicate and handle information using these new media. The demands include the ability to handle an increasingly diverse and complex range of texts. The diversity stems from access to large numbers of written, visual and aural texts from many cultures and countries and the complexity from the convergence of media and text types and their interrelationship (Leu \& Kinzer, in press). Learning environments in schools need to include both traditional environments as well as those characterised by the use of new technologies and more diverse and complex texts. Given the rate of social, cultural and technological change, new learning environments and text types will continue to emerge at an ever-increasing rate (Leu, in press). Within this framework it is essential that schools address how to provide students with the necessary skills and understandings to deal with new learning environments and the literacies needed to learn and work effectively within them.

\section{NEW TEXTS AND SOCIAL PRACTICES}

Text types, also known as genres, and social practices surrounding literacy are always evolving and changing. Key changes have occurred as society has moved from aural technologies to paper-based technologies, to analogue broadcast and communication technologies. Similarly, with the advent of the digital interactive technologies "new" or hybrid texts have emerged within the new environments created by these technologies. The new technologies have created a space for more creative and playful 
interactions with visual, spoken and written forms of making meaning, i.e. modes of representation. With the construction of these "new" texts come "new" ways of interacting with texts, as well as with people.

Some of the new texts are variations of "old" texts that use the new technologies as a medium to convey their messages. Hypertexts while similar in many ways to linear texts have non-linear structures. Multi-modal texts, combine and use the visual, aural and written modes in different ways. New texts are also being created within environments where the computer mediates communication, these texts seem to integrate features of written and aural texts. Similarly, some of the social practices have evolved from existing practices with traditional texts and others are significantly different. In the following sections, these new text types and practices will be discussed.

\subsection{Hypertexts}

Traditionally, paper-based texts are written on the basis that they are read in a particular sequence, from chapter one to the next chapter to the next, until the text is finished. They are linear texts. Hypertexts while similar in many ways to linear texts have non-linear structures (see Fig 1). They can have multiple pathways and multiple endpoints. The reader does not necessarily have a set beginning point, nor a set sequence of reading nor a set endpoint to the overall text.

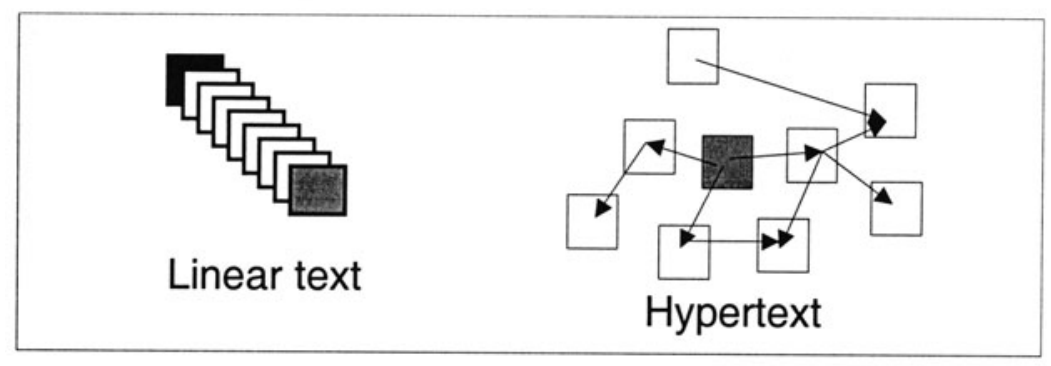

Figure 1. The structure of texts

Hot-linked words and navigation icons enable the reader to decide where to go, what screens and information sequence to engage with. The construction of meaning of the new text is influenced by the pathway the reader takes, the navigation icons and tools engaged with (Joyce, 1997), and ultimately the visual elements of each screen. The links and pathways that are provided are vital keys to tacit assumptions and values of the designer/author. 
Access to the information within hypertext environments depends on an individual's information skills, the search strategies they use to locate information and to extract information. This can be quite challenging since the organisational structure is not obvious, nor easily discerned. Many of the strategies developed with linear texts do not apply, new strategies are needed to effectively negotiate the various pathways. One of these strategies, surface reading, has become a means by which students can efficiently access information. Surface reading is akin to the "surfing" of the Internet. It is also the reading necessary in this type of environment as it enables students to be more adept at rapid screening and parallel processing of different materials simultaneously. The user is less inclined to attend to one text for sustained periods of time (deep reading). Also the quickness associated with this form of reading tactic enables users to view or read a large number of sites of information and make decisions about which to revisit and engage with more deeply. In effect for users of networked environments, like the Internet, a sustained attention span may be less useful than successive attending (Joyce, 1997).

\subsection{Multi-modal texts}

Many of these new texts incorporate a range of modes, not just the written and static visual, but also sound, video and animation. In an electronic environment it is easy to combine different modes of representation. Multi-modal texts have become the norm within networked environments, such as the Internet. In the past, the different modes were managed by experts. Now technology allows individuals to create and control all modes, including sound, with only limited skills.

For most electronic texts, it is the visual elements that dominate the screen, "the look" is important to all (Kress, 1997). Both the words and the images are visual elements and their development can be more easily controlled, designed and changed than in a paper-based environment. These visual texts place further demands on the reader, particularly where the images have taken over some of the functions of the words. The result being that written language has become less complex and the images more complex as they act as highly abstract representations of objects and relationships (Kress, 1997).

The reading of visual texts has been presumed to be easy, with the meaning of the images being considered transparent to the reader. While in one sense it is correct to think that images are easier to "read" than words, strategies and techniques used to construct meaning, and to position the "reader" in relation to the message are complex and subtle. For example the layout, composition, components of an image and its placement on a page in 
relation to the written text, all influence the understanding of the message by the reader.

\subsection{Computer Mediated Communication (CMC) texts}

Computer mediated communication has also generated a range of new texts in homes, workplaces and classrooms. These include texts in both synchronous and asynchronous environments. Examples of synchronous environments are chat rooms and MUD Object Oriented environments (MOOs). Within these environments individuals of any age can "speak" with other people from around the world or with their friends. The text is written but the mode is spoken. The interaction is socially oriented, with the development of a punctuated written text similar to overlapping speech during a conversation.

Email is yet another "new" text type that exists within asynchronous environments. It has a whole new set of social practices emerging around its use. Similar to those in IRCs, texts generated by users of email vary along the mode continuum between spoken and written (Yates, 1996). However, the asynchronous nature of email allows for a time delay and more fully developed texts. This enables the writer to use the rules and conventions of print-based texts in the formation of their texts. But there are differences between email and paper-based texts. For example, spelling does not have to be perfect; metalinguistic cues such as emoticons and "visual" signatures made of key strokes are used; there is an assumption of immediacy and closeness in distance when a message is sent. In many ways email represents the digital equivalent to a telephone message.

\subsection{The cultural dimension of new text types}

Within the new texts English tends to be the lingua franca. Not only does English dominate the texts published as sites on networks but the production is predominantly based in the United States of America (Yates, 1996). This dominance of English can be seen as cultural imperialism, which is developing from the internationalisation and globalisation of the networked society based on traditional western print-based culture (Luke, 2000). There are increasing numbers of sites emerging in different languages and from different cultures. As these sites increase, the Internet will readily afford users access to sites, texts and languages from all over the world. But it remains to be seen if the environment continues to be based on western cultural texts.

As teachers and students learn about and work with new texts, the demand for inter-cultural understandings creates another layer of complexity 
surrounding the new literacies. Traditionally, textbooks provided sources of information within the student's cultural framework. While there has been growing attention to how such texts position students from minority cultural and linguistic backgrounds, to date there has been little need to pay attention to Australian students accessing information texts created in other cultures and languages. Readers of the new texts will require the critical skills to determine the cultural and ideological meanings being conveyed in the texts. Authors will need to consider the variety of sociocultural backgrounds their readers may come from or to whom they may be writing.

Making meaning from images is also situated within cultural and social practices and exploring the visual layout of the screen reflects these practices. As most of the Internet is based on western culture, the screen is presented reflecting western text development: reading from left to right, top to bottom, frames placed in particular relationship to the page. The matter of cultural differences in visual representations (Iedema, 1998) and the way other cultures read "English" visual representations should be addressed as they are important aspects of critical visual literacy, essential skills for readers of "new" texts.

\subsection{Social practices surrounding new electronic environments}

Broader social practices with the new electronic environments impact on the way that secondary students interact with digital texts. One social practice, in particular, is likely to impinge on the effective use of digital texts for learning in the various subject areas in the secondary schools. This relates to the way that young people first encounter these new technologies in their homes and in broader society within the framework of popular culture. Young people in Australia are most likely to have their first encounters with digital interactive texts in the home in the form of computer games (Australian Bureau of Statistics, 1996). Through their experience of game playing, they develop particular orientations to the use of computer technologies (Downes, 1998). Some of these orientations generate beneficial outcomes for new learning environments in classrooms. They develop a general proficiency with the technology; they learn to deal with complex and ambiguous interactive multi-modal texts such as games by employing a "playful" or exploratory mode of learning. Within these informal learning environments visual feedback dominates and young people are used to being "in charge" of their learning and performance. On the other hand, a number of authors (Birkerts,1996) argue that computer game playing can have negative effects. For example, they argue that playing games generates trivial attitudes towards all virtual environments and consolidates pre- 
dispositions to high stimulus environments while reducing capacity to concentrate within less stimulating ones.

While these social practices relate more to the use of new texts within popular culture than within learning environments, they are part of the broader social framework within which students interact with the new technologies and texts. They generate attitudes and habits of thought that can be productively built upon or can create barriers to the effective use of these texts for learning. These issues need to be considered as part of the social practices surrounding the new digital texts.

\subsection{Broadening our definition of literacy}

It light of all the changes in the home, workplace as well as the school in relation to the nature of texts and the dominance of new text types, and the increasing volume and complexity of collections of texts it is important for educators to redefine literacy to encompass these "new" texts and the social, cultural and critical dimensions of their use.

To this end, a working definition has been devised to assist the development of new curriculum and pedagogical frameworks for both new and traditional learning environments in a global and digital world. This definition draws on elements from several different theoretical perspectives for example The New London Group (1995) and J.R. Martin (1992).

Literacy is the ability to locate, comprehend, use, create and be critical of a variety of texts and their accompanying social and cultural practices from diverse contexts, using a range of language modes, forms, features and structures.

In this definition, the key terms: modes, form, features and structure are drawn from the current NSW English Stage 6 Syllabus (1999). Modes of language refer to listening, speaking, reading, writing, viewing and representing. These modes are often integrated and interdependent activities used to make meaning, especially when working with multi-modal texts. Language forms and features refers to the symbolic patterns and conventions that shape meaning in texts. Structures of texts refers to the relationship of different parts of a text to each other, and to the text as a complex whole. For example some texts are linear, others such as hypertexts can be hierarchical or networked. 


\section{AN EMERGING CURRICULUM FRAMEWORK}

This broader definition of literacy provides a basis for developing a curriculum framework within which teachers in secondary schools can create new learning environments that use new technologies and new types of texts to support learning in their subject area. These new learning environments require the modification of existing practices and the generation of new practices. In particular it requires a re-evaluation of some common practices in paper-based learning environments in the light of their contribution to effective learning. For example, the practice of students independently completing "projects" is common in the junior years of secondary schooling. Yet, in Australia, it is generally done poorly with many students photocopying images, copying sections of written texts from books and sticking them on a piece of cardboard or in a folder. The students are representing information on the topic without having engaged deeply with the concepts and understandings inherent in the topic. Simply transferring this practice into a digital environment, by having the students construct a website, and applauding it because "it looks great" does not address the pedagogical issues surrounding the efficacy of the practice itself. At all times, it is important for students to learn about and work with a range of texts in order to develop and demonstrate their understandings within the particular subject area.

Figure 2 presents the curriculum framework needed for the new learning environments. It addresses the demands placed on learners that use traditional and new types of texts for learning about and engaging with their global and digital world. The outcome is the development of a multiliterate individual, who is able to be literate in several modes of representation, and able to apply their skills and understandings to new learning environments and other modes of representation. The essential skills of the multiliterate individual are locating, comprehending, using, critiquing and creating texts within personal, social, educational, historical, cultural and workplace contexts. In particular for secondary school students, this is embedded within the context of the curriculum in the different subject areas.

The actual diagram presents the intersection of the texts, media and processes required within new learning environments, whatever the subject area. The inner circle is labelled "Developing and demonstrating understandings". This emphasises that all teachers and all classrooms are literacy classrooms, where the teaching of literacy is in the service of a deeper engagement with the content of the subject area.

The next two layers represent the range of texts and media with which students engage in these classrooms. They include visual, aural and multimodal texts as well as the more traditional written texts. The media of these 
texts can be live (as in speeches and dramatic performances), paper-based or electronic. In addition, the framework recognises that these texts are part of social practices, that they may be part of a collection of texts, and not just individual items.

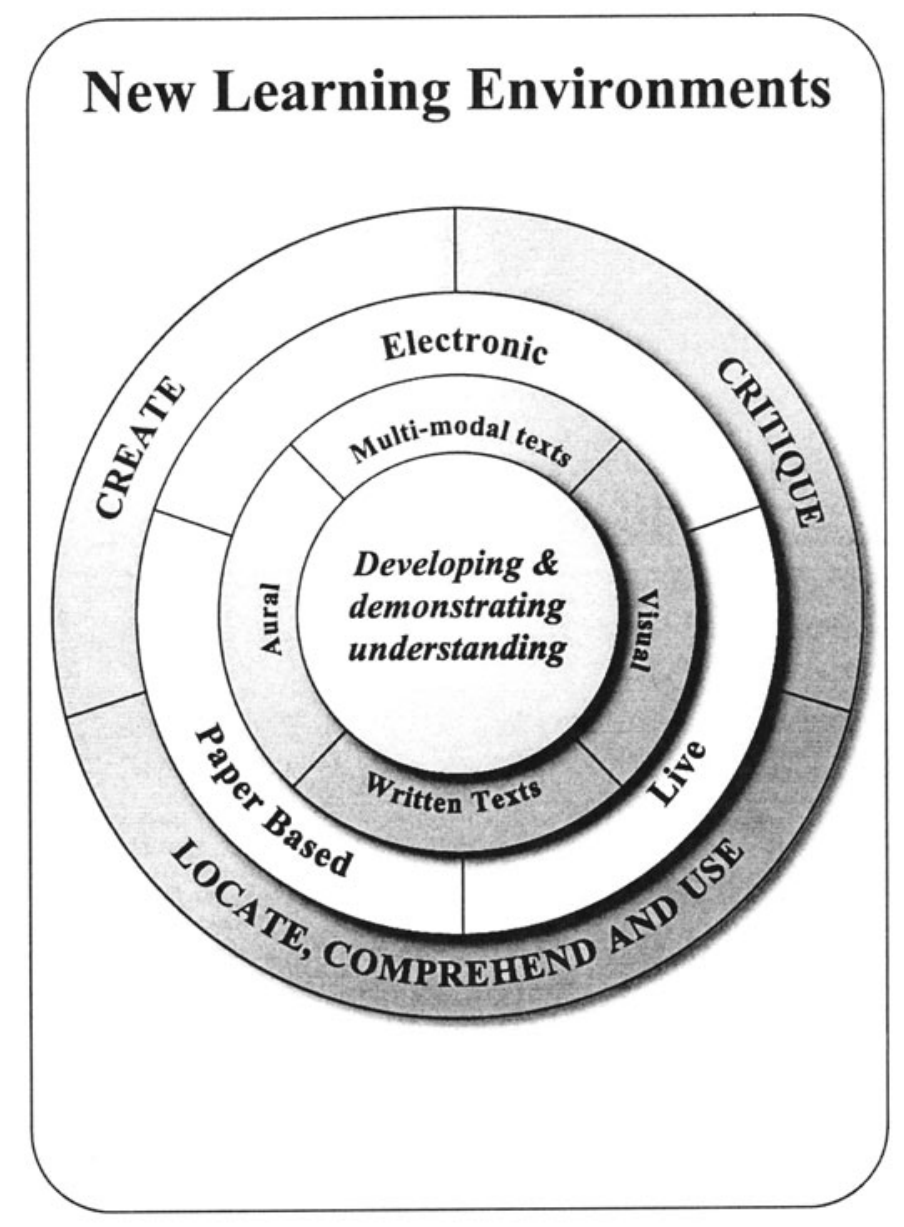

Figure 2. A curriculum model for new learning environments

The outer circle focuses on the processes of teaching and learning, within the class, as teachers and students work with texts. Equal emphasis is placed on three sets of processes: "locate, comprehend and use", "critique", and "create". For many years the emphasis has mainly been on the comprehension and use of texts. Locating texts has become a more strategic skill and is intertwined with "comprehending and using" as learners move from accessing limited, moderated and ordered collections such as those found in school libraries to accessing the chaotic, anarchic and almost 
boundless collection of texts in the Internet. Critiquing texts has been a common feature of literary and media studies for many years. However it is not a common practice in secondary curricula in relation to factual texts nor to the investigation of ideological stances within historical or scientific texts.

Similarly the creating of anything other than written texts has not been common in secondary classrooms. Students need to develop the skills to create texts in different modes and mediums. For example, students need to construct speeches, radio interviews, video, film, and multimedia texts such as web pages or hypertexts. They need to move beyond the viewing and critiquing of such texts and their production to the creation of their own texts for particular purposes and audiences. This takes for granted competence in the use of the media, and in the conventions and patterns used in these different types of texts. It also requires monitoring and evaluating the most appropriate media and text types for organising and presenting ideas and experiences in a variety of contexts.

To implement this framework for multi-literacies in new learning environments across the secondary school attention needs to be paid to both pedagogical practices and changes to curriculum. The key elements of these are:

- The pedagogy involves learning literacies, learning through literacies and learning about literacies. Learning literacies and learning about literacies will remain primarily the responsibility of the English, Art, Music, Drama and Design and Technology teachers. Learning through literacies is the responsibility of all teachers. All teachers need to engage in the explicit teaching of the various texts and processes within subject area classrooms to enhance the development and demonstration of subject matter understanding.

- The curriculum includes the teaching of metalanguages to provide the labels and tools with which teachers and students can explicitly describe and talk about the various texts. For example, students need a language to talk about visual (Callow, 1999) and aural texts as well as written texts. This requires co-operative planning so that English, Art, Music and Drama teachers who traditionally teach the metalanguages for the study of literary, aesthetic, and performed texts work in tandem with other subject matter teachers to develop ways of talking about factual texts in terms of their form, features and structures and their relationships to the cultural dimensions of the text.

Both of these present real challenges to teachers, many of whom have limited knowledge of the new technologies and who fear losing control over content delivery (Golman, Cole \& Syer, 1999). 


\section{CLASSROOM EXAMPLES}

In this section two examples are presented to highlight the nature of changes to the pedagogy and the curriculum that the new learning environments require. The first is an example from a History classroom and the second from a Geography classroom.

\subsection{A history classroom}

A class of modern history students (15-16 year olds) studied "The Cold War". Early in the unit of work the history teacher posed a series of questions to engage students in a critical reading of the written texts they were using to gather information about their topic from the school and local libraries: Whose history are they reading? Who wrote that history? What are the ideologies embedded in their accounts? How have they positioned East and West? Why have they positioned them in this way? What strategies have they used to position them?

In their English classroom, the students worked with selected written texts to critique how the form and features of these texts positioned the various events and people described in the text and how they positioned the reader in relation to the text. They wrote from particular perspectives, they read literature written by authors during the Cold War, about the Cold War and discussed the questions above and point of views. Similarly in the Art classroom, they worked with selected photos from texts about the topic to critique how the composition of elements, and the use of light portrayed the phenomena, events and people in particular ways.

Later in the unit of work the same critical questions were applied to a range of Internet sites found by the students during their search for information on the subject. Again the English and Art teachers provided support through critiquing the written and visual elements of these electronic texts. The teacher-librarian and history teacher reinforced the information skills necessary for searching, navigating and using the Internet. Students practised their surface reading skills, explicitly talking about where they went by printing out the history of their time on the computer.

As part of the assessment for the subject, students formed groups and produced a web page to link to the class history website. In the history classroom, they deconstructed and discussed the layout and visual design of web pages with similar purpose and content. Students were given different roles and tasks, to develop expertise and also content for their web page. The final product was a co-operative (joint) construction, a team effort. The 
key characteristic of the content of the web page was to present a variety of cultural and historical yet authoritative perspectives on the Cold War.

Scaffolding of the tasks was provided through contact with a range of "experts" and through explicit teaching and learning. The English and Art teachers provided explicit teaching about the form and features or particular texts. The Art and Design and Technology teachers became visiting experts for the production phase, offering advice on design and technical issues. Each student kept a journal about their experiences of producing the web page, including the ideological background of the site; whose position it was trying to give prominence to; why images, writing and sound texts were used; and reasons for the placement of texts in regards to supporting the message/s they were trying to convey to the reader.

\subsection{A Geography classroom}

A class of 12-13 year olds were studying deserts to deepen their understanding of the interactions between physical environments and their related human communities. As part of the assessment of this work, students worked in pairs to locate information about a particular desert and its human community and to create a multi-modal information report on their desert that would become part of a large hypertext on "Desert regions and their peoples".

A number of teachers worked co-operatively to improve the students' skills and understandings throughout the unit and to develop their literacy skills in the context of this work. The teacher librarian worked on the students' information handling skills in searching the library using the online catalogue, in searching the Internet using subject-based sites, and taking notes related to key questions generated in their Geography lessons. Also in these classes the issue of citing sources of information, and seeking permission from website owners to use images, sounds and graphics in their works were discussed and a model email was devised in the English classroom for students to use when writing for such permission.

The Design and Technology teacher, introduced all the students to the features of the "outline" view in word processing packages and its use for note taking and recording sources of ideas, images, and sound bites. As well, in the Design and Technology classroom the students looked at a range of multimedia factial texts and discussed design issues that made such texts easy to comprehend and use. A key issue to emerge was the function and relationship of the written and visual modes. As part of the design process the students discussed criteria for evaluating the design of their final information report. The students used computer lab time from both their 
Design and Technology, English and Geography classes to work on their reports.

As part of the process the English teacher explicitly taught the students how to generate information reports that have particular forms and features that work in screen-based environments. The Geography teacher used one of the existing online project networks to generate communication between the class and students who lived in many of the world's desert communities being studied. Email communication with these students was used not only to collect further information but to seek feedback on the final report. Again, the English teacher worked with the students to learn about the form and features of email messages, so that students would feel confident in introducing themselves to students in other countries, outlining their project and asking questions.

The Geography teacher concentrated on working with the students to organise and analyse the information they collected in ways that lead them to further understand the interaction of the environment and the its peoples and to present their findings in ways that highlighted this interaction. As part of this work, the class had a discussion about the overall structure of the hypertext; its key organising features (would it be organised around regions of the world, types of deserts, or developing and developed communities?) and the ways links could be used to highlight the commonalties and differences within the physical elements of the environments, lifestyles of the communities and their apparent interaction. As part of these discussions, the teachers and students developed criteria for evaluating the content of each pair's work on a particular desert/community as well as the whole hypertext as put together.

The actual construction of the whole hypertext, was done by a group of interested students outside of normal class time. This was done under the guidance of the Design and Technology teacher, but based on a design brief developed by the whole class and the Geography teacher and with feedback from the whole group. This approach took account of the limited timeframe of the unit of work, and the general skill level of the students. Each pair of students created a simple hypertext that demonstrated their understandings while the design of the whole hypertext, with its more complex features, reinforced the broader inter-relationship of environments and their human communities.

\section{CONCLUSION}

Co-operation and teamwork are essential aspects of learning in the new electronic and global environments, for both teachers and students. A 
curriculum framework that draws on the expertise of relevant subject specialists, those with the metalanguages (the language to talk about how the text is created, its form, features and structure) and technical skills, and those with the knowledge of the content will provide students with the tools they need to locate, comprehend and use, critique and create new text types. With this approach to literacy, or multi-literacies, students will be well equipped to work with new, and future, learning environments.

\section{REFERENCES}

Australian Bureau of Statistics. (1996) Household Use of Information Technology, Australia Catalogue No 8128.0, Commonwealth of Australia, Canberra.

Birkerts, S. (1996) The Gutenberg Elegies. The Fate of Reading in an Electronic Age, Faber and Faber, London.

Board of Studies, NSW. (1999) English, Stage 6 Syllabus, Author, Sydney.

Burbules, N. (1997) Rhetorics of the Web: Hyperreading \& critical literacy, in From Page to Screen: Taking Literacy into the Electronic Era (ed. I. Snyder), Allen \& Unwin, Sydney, 102-122.

Callow, J. (1999) Image Matters: Visual Texts in the Classroom, Primary English Teaching Association, Sydney.

Christie, F. and Martin, J. (1997) Genre and Institutions: Social Processes in the Workplace and School, Caswell, London.

Downes, T. (1998) Children's use of computers in their homes, PhD Thesis, University of Western Sydney.

Goldman, S., Cole, K., and Syer, C. (1999) The Technology/ Content Dilemma, paper presented to the Secretary's Conference on Educational Technology, [http://www.ed.gov/Technology/TechConf/1999/whitepapers/paper4.html].

Iedema, R. (1998) Culture-Specific Representations of Conflict: Bonnie \& Clyde (USA) versus The Runner (Iran), paper presented at the 25th International Systemic Functional Congress, Cardiff, U.K., 13-18 July.

Joyce, M. (1997) New stories for new readers: Contour, coherence and constructive hypertext, in From Page to Screen: Taking Literacy into the Electronic Era (ed. I. Snyder), Allen \& Unwin, Sydney, 163-182.

Kress, G. (1997) Visual and Verbal Modes of Representation in Electronically Mediated Communication: The Potentials of New Forms of Text, in From Page to Screen: Taking Literacy into the Electronic Era (ed. I Snyder), Allen \& Unwin, Sydney.

Lankshear, C. (1997), Changing Literacies, Open University Press, London.

Leu, D. and Kinzer, C. (in press) The convergence of literacy instruction with networked technologies for information and communication, in Reading Research Quarterly, 35 (1).

Luke, C. (2000) Cyber-Schooling and Technological Change: Multiliteracies for New Times, in Multiliteracies: Literacy Learning and the Design of Social Futures (eds. B. Cope and M. Kalantzis). Macmillan, Melbourne.

Martin, J. (1992) English Text: System and Structure, John Benjamin Publishing Co, Philadelphia.

The New London Group. (1995) A Pedagogy of Multiliteracies: Designing Social Futures, The NLLIA Centre for Workplace Communication and Culture, Sydney. 
Yates, S. (1996) English in Cyberspace, in Redesigning English: New Texts, New Identities (eds. S. Goodman and D. Graddol). Open University Press, London, 69-91.

\section{BIOGRAPHIES}

Toni Downes is an Associate Professor in educational computing at the University of Western Sydney. Her teaching responsibilities include educational computing, leadership and technology, and research methodologies. Her current research projects and consultancies span from early childhood education to university education. They include the development of an online course in quality leadership and technology, the investigation of the educational use of the Internet with young children, the changing nature of literacy, and the use of computers for teaching and learning in educational settings.

Katina Zammit is a Lecturer in language and literacy at the University of Western Sydney. Her teaching focuses on the learning of language and literacy in the elementary years, educational linguistics, and the intersection of literacy and technology. Her research interests revolve around the analysis and use of multi-modal texts for literacy learning and teaching. These include the analysis of multimedia environments from a sociolinguistic perspective, information skills for young children using hypertext environments and the development and use of on-line learning environments for the teaching and learning of literacy. 